\title{
Integration and collaboration of determinants of entrepreneurial competitiveness
}

\author{
P. Eko Prasetyo ${ }^{a^{*}}$, Andryan Setyadharma ${ }^{b}$, and N. Rahayu Kistanti ${ }^{\mathrm{c}}$
}

${ }^{a}$ Professor in Department of Development Economics, Faculty of Economics, Universitas Negeri Semarang, Indonesia ${ }^{b}$ Doctor in Department of Development Economics, Faculty of Economics, Universitas Negeri Semarang, Indonesia ${ }^{c}$ Lecture in Department of Development Economics, Faculty of Economics, Universitas Negeri Semarang, Indonesia

\section{H R O N I C L E}

Article history:

Received February 21, 2021

Received in revised format May

20, 2021

Accepted June 32021

Available online

June 32021

Keywords:

New Product Development

Institution

Productivity

Economic Growth

Competitiveness Progress

Performance

Sustainable Development

\begin{abstract}
A B S T R A C T
The advancement of sustainable competitiveness and its contribution to the sustainability of sustainable development are becoming increasingly important research topics in sustainability science. The main purpose of this study is to disseminate knowledge in the practice of entrepreneurship and to strengthen the theoretical foundation to support sound and appropriate decision making as well as to improve the performance of the business competitiveness. The main source of data material in this paper is the primary micro fundamental survey with path analysis model. The result of this study shows that technological innovation not only produces new products but can also be the best way to achieve advancement. New Product Development (NPD) is the output of technological innovation, and the best way that must be developed as a strong foundation for decision makers to achieve sustainable competitiveness progress is the new product development and institutional integration. If productivity and economic growth are the main keys to success in achieving sustainable competitiveness, the NPD and institutional integration is the main determinant of the progress of sustainable competitiveness. The conclusion of this study is that productivity and economic growth is not enough to be the main key of the strength of competitiveness, but it also requires collaboration from various fundamental factors and the NPD and institutional integration as a driving force, the best way, and the main determinant of the achievement of the performance progress of sustainable development competitiveness.
\end{abstract}

\section{Introduction}

The linkage between the accumulation of human capital, institutions, entrepreneurship, and new products in sustainable development has become an increasingly interesting topic of debate over the past decade (Urbano et al., 2019; Chowdhury et al., 2019; Aparicio et al., 2018, 2019; Acs et al., 2018). Theoretically, human capital has been believed to be positively related to economic growth (Ali et al., 2018; Pelinescu, 2015; Prasetyo, 2020b). Human capital development is an important determinant of long-term sustainability (Šlaus \& Jacobs, 2011). Intellectual resources are the main driver of competitiveness in the knowledge economy (Rađenović \& Krstić, 2017). The linkage of intellectual capital and sustainable regional competitiveness is strong and inseparable (Januskaite \& Uziene, 2018). On the other hand, the main determinant of crosscountry differences in per capita income is the differences in the economic institutions (Acemoglu \& Robinson, 2010). Institutional economics has tried to find the main cause of differences in economic development between countries (Arzenšek et al., 2016). Furthermore, the study from Acemoglu et al. (2014) has focused on institutions as a fundamental determinant of sustainable development. Therefore, the main urgency of the problem in this paper stated that an integrated pragmatic approach is still needed to show the most important factors, and which are the main factors that are in fact the main determinants of progress and the main driver of sustainable development. A pragmatic approach is used to show that several important factors need to be addressed appropriately, so that the use of these resources enables it to contribute to sustainable development (Rosen, 2009). In addition, it is still necessary to integrate sustainability with manufacturing and design, along

* Corresponding author

E-mail address: pekoprasetyo@mail.unnes.ac.id (P. E. Prasetyo)

(C) 2021 Growing Science Ltd. All rights reserved.

doi: $10.5267 /$ j.uscm.2021.6.002 
with other objectives such as function, competitiveness, profitability, and productivity (Rosen \& Kishawy, 2012). Moreover, the results of the research from (Rosen \& Kishawy 2012) concluded and recommended that broader research and collaboration are needed to improve the understanding of sustainability in design in order to increase technology transfer and application of sustainability.

The main urgency of the specific problems in this study is how the important role of NPD as an output of technology transfer results and the role of institutions as a way or rule in increasing the technology transfer in an integrated manner can increase productivity, economic growth, and sustainable competitiveness. The argumentation is that the integration of the role of NPD and institution is considered important and must be handled appropriately, so that it can be a strong guideline for optimizing the use of human capital and social capital resources, as well as being able to maximize the performance of productivity, economic growth, and sustainable competitiveness (Prasetyo, et al., 2020a, 2020b; Prasetyo, 2019). The basic novelty of this study is to continue the recommendation from the research results from Rosen (2009); Rosen and Kishawy (2012), who stated that sustainable integration and collaboration is still needed in increasing technology transfer and sustainable application. This design is made because the integration and collaboration design is still considered new and important to enhance the understanding of the role and function of sustainable development. Popescu et al. (2017) has used hierarchical clustering methodology to evaluate global competitiveness in a sustainable development model by using four indexes, namely: human development index, environmental performance index, global competitiveness index, and GDP per capita. The research model from Anatoliy et al. (2019) has developed a methodological approach to economic institutional models by sharing the formation of human capital, as well as the causes and prospects for their development. However, the research results of the two researchers still cannot be used as guidelines and explain with certainty about the most important and best integrated factors that become the main determinant in improving the performance progress of sustainable development competitiveness, so that the previous results have not been able to be used for policy implications properly and right.

The specific purpose of this paper is to explain more pragmatically about the important role of NPD and institutional integration as the best main determinant in improving the performance progress of sustainable development competitiveness. The capacity integration of NPD and institutional factors can be considered as a process, guidelines, as well as the main and most important determinants because it can further optimize the use of resources and maximize results, so it must be handled properly and explained more simply. Therefore, it can be more easily understood and utilized to achieve the performance progress of sustainable development competitiveness. With the transfer of innovation technology, through backward linkages, the use of resource optimization can be achieved more efficiently. Moreover, with the integrated action through forward linkages, it is expected to be able to maximize the output performance and outcome more effectively, especially in the achievement of improved productivity, economic growth, and sustainable competitiveness performance. The basic literature argument is that political and economic institutions affect the productivity of resource use (Hall and Sobel, 2008). The research hypothesis from Hall and Sobel (2008) has proven that institutions affect economic growth, primarily through their influence on entrepreneurship and discovery.

\section{Literature review}

Recent literature studies that focus more on the linkage between institutions and entrepreneurship, as well as entrepreneurship and economic growth have been conducted by Urbano et al. (2019). The research results from Urbano et al. (2019) have found the domination of institutional approach in the 2012-2016 research period, and concluded that institutions influence entrepreneurship, but informal institutions have higher and more positive influence than formal institutions. On the other hand, entrepreneurship has been recognized as the main channel for sustainable development products and processes (Hall \&d Sobel, 2008). However, the role of entrepreneurship in achieving sustainable development goals is still an important subject of interesting debate in recent years (Dhahri \& Omri, 2018; Boudreaux, 2019). The research results from Dhahri and Omri (2018) simultaneously showed that entrepreneurship positively increased economic growth and improved the social conditions of sustainable development in developing countries, while the contribution for environmental dimension is negative. The results of the studies from Boudreaux (2019) by using the GEM data have found that entrepreneurship drives economic growth, but not in developing countries. This means that the findings of the two preliminary studies already have important and good policy implications, including in developing countries, but it still needs to be done with extra caution. The novelty of this research methodology is that this study uses empirical research method in developing countries in Indonesia by utilizing micro fundamental survey data to be able to explain more simply, and easily understood the role of the main resource linkages: human capital, social capital, productivity, economic growth, NPD, and institutions as the main and most important collaborative issues in improving the performance progress of entrepreneurship industry competitiveness.

Recent literature studies that have examined the linkages between institutions, entrepreneurship, economic growth outcomes, and more focus on empirical research have been carried out by Aparicio et al. (2018); Bjørnskov and Foss (2016) and Acemoglu et al. (2014). The research from Aparicio et al. (2018) using the panel data has found that institutional factors drive entrepreneurial opportunities to achieve higher levels of economic growth, and it is also found that entrepreneurship is relevant for economic growth. In addition, one of the research results from Bjørnskov and Foss (2016) emphasized that economic growth is an important political purpose, but entrepreneurship is most often used to explain differences between countries (and regions) in the level of economic activity. This means that the result of the study is a consequence, and there is no development of new theories that provide stronger guidelines for empirical studies of the linkage between economic growth and entrepreneurship. The results of empirical research with the NPD value chain strategy model have been able to provide 
new effective theoretical contributions as an option for progressive institutional policy interventions (Prasetyo \& Dzaki, 2020). The empirical research model from Acemoglu et al. (2014) who have treated institutions and human capital as exogenous variables is not specifically determined, either for reasons of variable bias or measurement errors. Therefore, the urgency of novelty and originality of this study empirically suggests the importance of the integration and collaboration of various fundamental resource factors, such as human capital, social capital, NPD, and institutions in influencing the performance progress of entrepreneurship industry productivity, economic growth, and competitiveness advancement. The subject of the special study of this paper is the fundamental factor that and naturally become a central issue, both in das-Solen and das-Sein. The specific purpose of this study is to explain the key important role that can be the main guidelines and determinants in driving the performance improvement of quality economic growth and the advancement of sustainable development competitiveness. Besides, the novelty and originality of the literature study of this empirical research have treated human capital and institutional variables as exogenous variables with the development of new dimensions that are controlled more rigorously, thoroughly, and prudently (Prasetyo \& Dzaki, 2020). Furthermore, the results of empirical research show that government spending has a positive and significant contribution to small and medium enterprises, but the effect is not significant for micro enterprises (Prasetyo, 2020).

In economic theory, there is no doubt that human capital investment will encourage productivity and positively correlate with economic growth. The research result from Pelinescu (2015) found that slow investment in human capital will affect the country's sustainable development. As one of the temporary solutions, the results from Aparicio et al. (2019), found that informal institutions throughout the country offset the lack of individual factors for those who have no entrepreneurial intentions. In addition, the theoretical model by developing a micro panel data model to explain the relationship between human capital, institutions, and economic growth has been carried out by Dias and Tebaldi (2012). This theoretical model shows that the improvement of institutional quality encourages the accumulation of human capital that comes from endogenous processes, which then reduce the income and change historical development pathways (Dias \& Tebaldi 2012). The results of another literature study that can strengthen the arguments of this paper is that encouraging the use of collaboration in regional economic development has become increasingly prevalent over the past few decades, and has been carried out by policy makers, both formal and non-governmental institutions (Bruce, 2014).

\section{Materials and methods}

This study is an empirical research designed with descriptive quantitative research design to explain the main fundamental factor that in real and natural terms becomes the central issue in the practical activities of entrepreneurs in the entrepreneurship industry. The needs of the main data material in this study are primary data obtained by survey, and secondary data as supplementary data. The details of material requirements and the analytical methods used in this study are explained in the following detail.

\subsection{Data Sources}

The main data source in this study is primary data, which is obtained by survey about the household behavioral activities of the MSME entrepreneurship industry in 16 districts and cities in the two provinces of DIY and Central Java. The main data source as analysis material is obtained from 125 entrepreneurs of the entrepreneurship household industry, which are taken in a representative manner from 256 populations based on the level of homogeneity of population characteristics. The basic characteristics of the population are identified based on the average growth of the business sector over the past five years, and several active and productive workforce who come from the local resources wisdom. Thus, there is no starter entrepreneurship industry that is surveyed. However, in terms of labor, it is not distinguished whether they are paid labor or unpaid labor that is a member of a household. In addition, the entrepreneurship household industry must remain active in carrying out its business activities for at least the last three years as a material for its business development survey. The sampling method is carried out using cluster sampling probability techniques, which are representative in the cluster based on the nature and character of ownership of the main business based on the utilization of local cultural wisdom resources and other creative business. The types of business sectors in the entrepreneurship industry are diverse, namely: the batik industry, food and beverage, agribusiness and agro-industry, the trade business, as well as handicraft industry and other creative industries. Based on these provisions, the analytical material data collection can be obtained from as many as 125 samples of entrepreneurial households and can already be considered representative.

\subsection{Definition of Operational Variables}

If NPD is the result of innovative technology and institutions as a rule or method, then the concept of integration in this research is interpreted as an integrated whole, especially regarding the results and methods. Meanwhile, collaboration in this paper is interpreted as an interaction between various fundamental factors of competitiveness determiners. In this study, various fundamental factors have been identified such as: human capital, social capital, productivity, NPD, institutions, and economic growth. Thus, the concept of collaboration integration in this study is considered as a rule of the game in which there are interactions of various fundamental factors involved in this research as an effort to achieve sustainable competitiveness progress. NPD and institutional integration has become a rule of the game which is adopted because it is considered the most prominent or the best of the various other related rules. The specific objective of the adoption of such 
integration is because it can optimize the use of available resources efficiently and better. It also can be a guideline and/or determinant of effective and adaptive output maximization in achieving sustainable competitiveness progress. Partially, the concept of NPD refers to sustainable development, while the institutional concept refers to the process or the best way to achieve sustainability development. Therefore, to achieve these objectives, NPD and institutional integration is needed to achieve progress in the performance progress of sustainable competitiveness and sustainable development.

All variables used in this study are variables that have been measured carefully with the measurement dimension of the index value ratio scale. The method for index value measurement used the Gini Ratio index value dimension, which is already well established and widely known to academicians, so there is no need to write it down in detail in this paper. However, in the previous paper, an outline of the method has been written in sufficient detail (Prasetyo et al., 2020b). This paper only presented a few selected variables based on the very rigorous experimental texts on previous models. From the results of the test, several selected variables used in the model of this paper, and econometrics has been assumed to be the best models of all existing models. The model is the best choice of model results of the experimental tests in the previous stage, including econometrics that has been declared to pass the classic assumption test. Finally, according to the objectives in this study, several variables can be selected and decided, namely: human capital, social capital, institutional, NPD, productivity, and regional economic growth, which are considered as exogenous variables; and industry competitiveness as endogenous variables.

\subsection{Analysis Method}

The analysis method used in this study is the path analysis method. The main purpose of this analysis technique is to better track and analyze the real main role (das-Solen and das-Sein) from exogenous variables (resources) to endogenous variables (output of the entrepreneurship industry competitiveness), both directly, indirectly, and in total. Based on the magnitude of the value of the path analysis, the most dominant path coefficient value can be obtained, and then this value is used as a fundamental guideline to state the important role or the main determinant. Furthermore, based on the initial direction of the most dominant path of analysis, it can be considered as the main or first role. To see the collaboration integration between related variables and to strengthen the basis of these arguments, the correlation matrix value approach of Karl Pearson Product Moment is preferred to be used than the value of the main regression coefficient and the path coefficient value. Therefore, this study tends to use the path analysis model in the form of a recursive correlated path model for multiple paths.

To be more easily understood, after several variables that are used is known and before compiling a path diagram model, a structural equation model must be arranged first. In this study, six structural equation models are presented, which are related to the subject matter and objectives of the study. As for the form of recursive system, in this case it can be interpreted that the relationship and the direction of influence of the path are in the direction of the exogenous variable to the endogenous variable, and that do not apply otherwise. The structure of the chosen path analysis structural equation model referred to in this paper can be arranged as follows:

$$
\begin{aligned}
& Y_{1}=\rho Y_{1} \cdot X_{1}+\rho Y_{1} \cdot X_{2}+\varepsilon_{1} \\
& Y_{2}=\rho Y_{2} \cdot X_{1}+\rho Y_{2} \cdot X_{2}+\varepsilon_{2} \\
& W_{1}=\rho W_{1} \cdot X_{1}+\rho W_{1} \cdot X_{2}+\rho Y_{1} \cdot W_{1}+\varepsilon_{3} \\
& W_{2}=\rho W_{2} \cdot X_{1}+\rho W_{2} \cdot X_{2}+\rho Y_{2} \cdot W_{2}+\varepsilon_{4} \\
& Z=\rho Z \cdot Y_{1}+\rho Z \cdot Y_{2}+\rho Z \cdot W_{2}+\varepsilon_{5} \\
& Z=\rho Z \cdot Y_{1}+\rho Z \cdot W_{1}+\rho Z \cdot W_{2}+\varepsilon_{6}
\end{aligned}
$$

Based on the structural equation form mentioned above, the path analysis diagram model referred to in this study can be described as follows in Fig. 1.

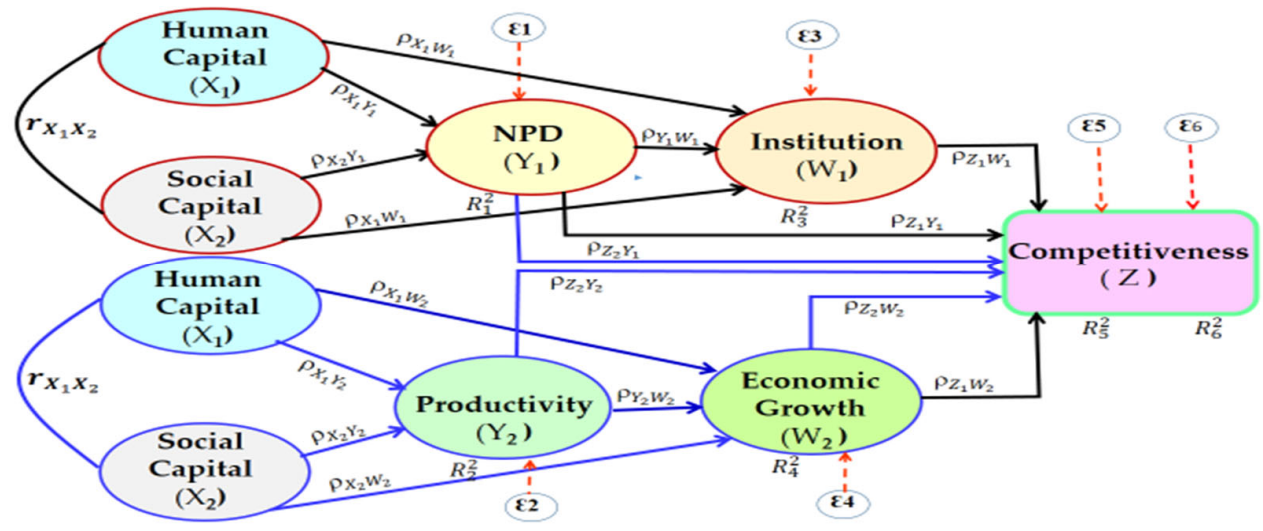

Fig. 1. The concept of the path analysis diagram model of multiple path correlational recursive form 


\section{Analysis Results and Discussion}

The purposes of modern development are not enough to only achieve the performance progress of sustainable development competitiveness, but it must be directed to achieve sustainability development. The role of productivity as the main driver of economic growth and the main key to competitiveness is no doubt. However, in order to achieve sustainable competitive performance in a sustainable manner, integration is still needed between NPD and institutions that collaborate with various key factors of human capital, social capital, and high-quality productivity and economic growth. The productivity indicator component has also become the latest trend and broad overview of experts and researchers. In the current era of globalization, the low performance of the entrepreneurship industry and MSMEs in Indonesia as a developing country is a fundamental issue, and the low performance of competitiveness is also a prudential problem that must be overcome to achieve the development advancement in the future. If this prudential problem of low competitiveness is not overcome as soon as possible, the multiplier negative effect that it causes will increasingly threaten sustainable development. The results of the previous research have also stated that low productivity has an impact on the low competitiveness of industries in the regions and the country of Indonesia as a whole. The low national competitiveness is reflected in the low productivity and entrepreneurship industry competitiveness in regional MSMEs. This means that the more competitive the entrepreneurial industry and MSMEs in the regions of cities in Indonesia are, the more competitive the competitiveness progress of a sustainable national economy.

In this paper, institutions are more interpreted as rules of the game or as facilitators, while technology is seen as the best and innovative way of human creativity to maintain its survival, so that technology does not have to have sophisticated machines; it is more important to be able to obtain the best results and/or the best way. In the era of the industrial revolution 4.0 and the era of technological innovation, there will be dynamic and adaptive economic conditions as well as increasingly competitive competition between industries, regions, and countries. These conditions encourage governance (institutions) to be able to change and anticipate them. This process of change is often described as a shift from a traditional institutional governance mode to a mode that is more entrepreneurial and fuller of political, economic, and socio-cultural risks. In the beginning, entrepreneurship was often used only as political jargon to encourage economic growth. Although the purpose of this model is good, it has not yet been declared successful, since the empirical evidence of the "triple track strategy" policy model in Indonesia has been declared a failure. These problems present new challenges and become a starting point for recommendations for research which results are briefly presented in this study.

Table 1

The Results of Regression Path Analysis Model of Recursive Double Path Model

\begin{tabular}{|c|c|c|c|c|c|c|}
\hline \multirow{2}{*}{ Model } & & \multicolumn{2}{|c|}{ Unstandardized Coefficients } & \multirow{2}{*}{$\begin{array}{l}\text { Standardized Coefficients } \\
\text { Beta }\end{array}$} & \multirow{2}{*}{ T-stc. } & \multirow{2}{*}{ Sig. } \\
\hline & & $\mathrm{B}$ & Std. Error & & & \\
\hline \multirow{3}{*}{1} & (Constant) & 0.154 & 0.042 & & 3.64 & 0 \\
\hline & Human_capital (X1) & 0.371 & 0.087 & 0.352 & 4.26 & 0 \\
\hline & Sosial capital (X2) & 0.417 & 0.095 & 0.361 & 4.373 & 0 \\
\hline \multicolumn{7}{|c|}{ Model-1: Dependent Variable NPD (Y1) } \\
\hline \multirow{3}{*}{2} & (Constant) & -0.088 & 0.041 & & -2.162 & 0.033 \\
\hline & Human_capital (X1) & 0.393 & 0.084 & 0.333 & 4.668 & 0 \\
\hline & Sosial_capital (X2) & 0.655 & 0.092 & 0.507 & 7.101 & 0 \\
\hline \multicolumn{7}{|c|}{ Model-2: Dependent Variable Productivity (Y2) } \\
\hline \multirow{4}{*}{3} & (Constant) & 0.143 & 0.019 & & 7.384 & 0 \\
\hline & Human_capital (X1) & 0.283 & 0.041 & 0.349 & 6.97 & 0 \\
\hline & Sosial_capital (X2) & 0.288 & 0.045 & 0.325 & 6.459 & 0 \\
\hline & New Product & 0.313 & 0.039 & 0.407 & 7.953 & 0 \\
\hline \multicolumn{7}{|c|}{ Model-3: Dependent Variable Institutional (W1) } \\
\hline \multirow{4}{*}{4} & (Constant) & 0.037 & 0.032 & & 1.171 & 0.244 \\
\hline & Human_capital (X1) & 0.574 & 0.07 & 0.556 & 8.219 & 0 \\
\hline & Sosial_capital (X2) & 0.246 & 0.084 & 0.218 & 2.941 & 0.004 \\
\hline & Productivity (Y2) & 0.136 & 0.069 & 0.156 & 1.971 & 0.051 \\
\hline \multicolumn{7}{|c|}{ Model-4: Dependent Variable Economic Growth (W2) } \\
\hline \multirow{4}{*}{5} & (Constant) & -0.115 & 0.03 & & -3.862 & 0 \\
\hline & Product & 0.237 & 0.065 & 0.25 & 3.648 & 0 \\
\hline & Institutional (W1) & 0.533 & 0.09 & 0.433 & 5.901 & 0 \\
\hline & Economic Growth & 0.28 & 0.064 & 0.289 & 4.408 & 0 \\
\hline \multicolumn{7}{|c|}{ Model-5: Dependent Variable Competitiveness (Z) } \\
\hline \multirow{4}{*}{6} & (Constant) & 0.007 & 0.025 & & 0.301 & 0.764 \\
\hline & Product & 0.361 & 0.065 & 0.381 & 5.534 & 0 \\
\hline & Productivity (Y2) & 0.168 & 0.054 & 0.198 & 3.132 & 0.002 \\
\hline & Economic Growth & 0.383 & 0.065 & 0.395 & 5.845 & 0 \\
\hline
\end{tabular}

Source: Processed Primary Data

The development of the various products is the result of new product management, which subsequently in this study is often referred to as new product development (NPD). The NPD includes design, concept, development, marketing, new services, new motives, and new principles. The purpose of NPD in this study is to help develop products to meet the needs of consumers and to maintain and enhance industrial added value and the sustainable competitiveness advancement. In this case, it is realized 
that not all products are favored by consumers or markets, because it requires integration and collaboration with existing institutions to be able to maximize results and optimize the resources used. The results of the study confirm that the product development carried out is not enough to only achieve efficiency and effectiveness, but it must be creative, innovative, disciplined, adaptive, and systematic to remain preferred by consumers and new markets. Furthermore, for the results of the development of new products to be more prospective towards the progress of sustainable development competitiveness, an institutional role must still be needed. Quantitatively, the description of the important role of new product development can be increasingly clearer and stronger when viewed from the results of the research in Model 1, Model 3, Model 5, and Model 6, in Table 1, and Fig. 2. Entrepreneurship industry competitiveness has an important role for sustainable economic development in a region. Through an effort of the performance improvement on entrepreneurship competitiveness, it can create productivity, employment, and other added values in a sustainable manner, which in turn can achieve increased community welfare. The results of previous studies have found that human capital capacity is the main driver of economic growth, and social capital factor is the main determinant of sustainable competitiveness. The novelty of the results in this study strengthens the previous studies and can emphasize that it is found the dominant role of institutional and social capital factors that are positively more able to encourage progress in improving the sustainable competitiveness of the entrepreneurship industry in the region to improve the welfare of the people's lives. Based on the research results in Table 1 and Fig. 2, it can be described that the factor of social capital capacity is able to drive an increase in NPD and productivity, which subsequently the increase of NPD can encourage the formation of economic institutional factors to be better. This economic institutional capacity factor will drive the progress of sustainable competitiveness. Therefore, integration between social capital, NPD, and economic institutional factors is very important and very necessary to further enhance the progress of sustainable competitiveness. The statement arguments can be explained based on the research results in Table 1 and Fig. 2. Based on the standardized beta coefficient value in Table 1 and the research results in Model 6, it appears that the research results still support the basic theory of established competitiveness and various previous research results, which stated that economic growth and productivity are the main keys of the driver of the advancement of sustainable competitiveness improvement. The originality and novelty of the results of this study is presented in Model 5, which shows that institutions are the main dominant factor in the improvement of sustainable competitiveness progress. This means that the empirical research result in Model 5 can be used as a guideline for strengthening the theory of competitiveness improvement in Model 6 and as a paradigm of the development for the basic concept theory of new institutional economics (NIE). In Model 5, it is examined further with backward linkages about what factors that are most dominant in influencing the institution. Then, in Model 3, it appears that NPD is the main dominant factor that drives these institutional factors. Furthermore, if it is traced further specifically, what is the first resource factor that drives competitiveness? The result of this research is increasingly clear in Model 1 and Model 2, that the first and foremost driving factor for increasing NPD and productivity is a strong collaboration of human capital and social capital resource capacity factors. The determinant of correlation in Model 1 can provide a strong correlation of 62 percent, and in model 2 it can provide a stronger correlation of 73.5 percent. If it is seen more specifically and carefully, the novelty of this research result in Model 1 and Model 2 shows that the social capital resource factors contribute more, both to NPD and productivity, than human capital capacity factor. This means that the argumentation based on the research results have strengthened the statement above and the results from previous studies (Prasetyo \& Dzaki, 2020; Prasetyo et al., 2020a). Specifically, it can be seen on Table 1 that the social capital factor by empirical practice in the entrepreneurship industry in regions has had a greater influence on the determination of NPD and the level of productivity.

Quantitatively, the evidence of the value of other research results novelty in this study based on Table 1 in Model 1 and Model 2 above shows that partially the standardized beta coefficient value of social capital capacity is more capable to provide the first largest contribution, namely 36.1 percent of NPD and 50.7 percent of productivity. Meanwhile, based on Model 3 and Model 4, the human capital factor capacity partially has a bigger role in improving institutions and economic growth. This result strengthens the argumentation of the importance of collaboration and integration between various fundamental factors as a guideline and the main source of determinants to increase sustainable competitiveness. Furthermore, it can be decided that NPD and institutional integration is the main guideline, determinant, and the main driver for the progress of sustainable competitiveness. It is explained above that technology not only produces better output (NPD), but it also must be done in the best way (institutional) as a rule of the game as well as a unified whole. Specifically, this observation is consistently strongly supported by the results of the research in Table 2 in Model 3 and Model 5 with the value of determinant correlation of 89.7 percent and 88.8 percent. Model 3 shows that econometrics determinant is the best model of the experimental results of the six existing structural models. This argument is what led to the title of this study, namely: NPD and Institutional Integration as the Main Determinant of the Progress of Sustainable Competitiveness. It is because collaboration and integration can obtain more optimal results and outcomes with the use of optimal main resource production factors. The research results of the experiment models in Table 1 and 2 are the results of the experimental research of the best econometrics model which has passed the classical assumption test.

Statistically, the research results from Table 1 and Table 2 can be stated as homoscedasticity, and there is no case of autocorrelation and multicollinearity, so statistically it can be accepted as a good and efficient estimator (BLUE). The research results in this study are different from the results of previous research in the role of productivity, which is no longer the main key, although the role is still positive and significant on the improvement of competitiveness. However, this research result is still in line with the results of previous research Prasetyo Prasetyo et al. (2020a, 2020b) who stated that the role of human capital as the main determinant in increasing economic growth, and the role of social capital is more important to encourage 
sustainable competitiveness. The research results in Table 1 and Diagram 2 show that the impact of the decline of the role of the main resource of human capital on NPD and productivity has been proven to have a continued impact on the decline of the main role of productivity as the main key for sustainable competitiveness progress. The phenomena of this research results turns out to be a new novelty that specifically become the main topic of critical analysis discussed in this study.

Table 2

Determinant of Path Analysis Regression Coefficient

\begin{tabular}{|c|c|c|c|c|c|c|c|c|c|c|}
\hline \multirow[b]{2}{*}{ Model } & \multirow[b]{2}{*}{$\mathrm{R}$} & \multirow[b]{2}{*}{ R Square } & \multirow[b]{2}{*}{$\begin{array}{l}\text { Adjusted R } \\
\text { Square }\end{array}$} & \multirow{2}{*}{$\begin{array}{l}\text { Std. Error of the } \\
\text { Estimate }\end{array}$} & \multicolumn{5}{|c|}{ Change Statistics } & \multirow{2}{*}{$\begin{array}{l}\text { Durbin- } \\
\text { Watson }\end{array}$} \\
\hline & & & & & $\begin{array}{l}\text { R Square } \\
\text { Change }\end{array}$ & F Change & dfl & df 2 & $\begin{array}{c}\text { Sig. F } \\
\text { Change }\end{array}$ & \\
\hline 1 & .620 & .384 & .374 & .209170 & .384 & 38.025 & 2 & 122 & .000 & 1.863 \\
\hline \multicolumn{11}{|c|}{ Model-1 (Predictors: (Constant), Sosial_capital, Human_capital and Dependent Variable: NPD) } \\
\hline 2 & .735 & .540 & .533 & .202197 & .540 & 71.657 & 2 & 122 & .000 & 1.587 \\
\hline \multicolumn{11}{|c|}{ Model-2 (Predictors: (Constant), Sosial_capital, Human_capital and Dependent Variable: Productivity) } \\
\hline 3 & .897 & .804 & .800 & .091024 & .804 & 165.907 & 3 & 121 & .000 & 2.112 \\
\hline \multicolumn{11}{|c|}{ Model-3 (Predictors: (Constant), NPD, Human_capital, Sosial_capital and Dependent Variable: Institutional) } \\
\hline 4 & .808 & .653 & .644 & .154480 & .653 & 75.765 & 3 & 121 & .000 & 2.237 \\
\hline \multicolumn{11}{|c|}{ Model-4 (Predictors: (Constant), Human_capital, Sosial_capital, Productivity and Dependent Variable: Economic growth) } \\
\hline 5 & .888 & .789 & .784 & .116432 & .789 & 150.948 & 3 & 121 & .000 & 1.694 \\
\hline \multicolumn{11}{|c|}{ Model-5 (Predictors: (Constant), Institutional, Economic_growth, NPD and Dependent Variable: Competitiveness) } \\
\hline 6 & .865 & .749 & .743 & .127077 & .749 & 120.244 & 3 & 121 & .000 & 1.641 \\
\hline \multicolumn{11}{|c|}{ Model-6 (Predictors: (Constant), Economic growth, NPD, Productivity and Dependent Variable: Competitiveness) } \\
\hline
\end{tabular}

In institutional theory, the institutional environment is often regarded as a set of basic social, political, legal, and economic rules that define human behavior. However, the results of this study found that economic institutions tend to be formed from the institutional environment of native and natural social entities that follow the behavior patterns of family social entrepreneurial activities in certain area, so that they are not like artificial institutions, such as from theory $\mathrm{X}$ and $\mathrm{Y}$ in companies (Radiva, 2018; Kirdina-Chandler, 2017, 2019). According to the research results from Radiva (2018), the development of corporate institutional economy was revealed based on innovation under the influence of globalization and monopolization, as well as corruption that changed individual institutions from the basic Y to X matrix. According to KirdinaChandler (2019), the Western institutional model is characterized by the dominance of a set of Y-matrix, including market economic institutions, federal political structures, and individualistic ideologies. Meanwhile, non-Western economic institutional models are distinguished by the dominance of a set of X-matrix institutions, including redistributive economic institutions, centralized political structures, and communitarian ideologies.

The critical analysis of this research results tends to be more like the results from Anatoliy et al. (2019) who stated that the influence of institutional environment is presented as human capital formed under the influence of a particular institutional system, and its actual ability to produce dirty products decreases from effective use to ineffective to manage the human capital. The influence of human capital on the environment becomes ambiguous because human capital cannot be separated from individuals, and it becomes unique at the personal level (Anatoliy et al., 2019). The research results from Anatoliy et al. (2019) emphasized that one of the main conditions for the development of a sharing economy is the new quality of human resources as its main assets, which also becomes its structural components at all stages. Based on the results in Table 1 in Model 1 and Model 2, as well as the results in Diagram 2, it appears that the role of human capital is smaller than the role of social capital on NPD and productivity, and the subsequent impact of the key role of productivity on power competitiveness also becomes weaker. The main cause of the weakness of the individual human capital factor is the role of informal institutions that share with individuals and those who do not yet have entrepreneurial ventures. However, as the main source, both theoretically and empirically, the role of human capital in Model 3 on institutions and the role of human capital on economic growth in Model 4 are still bigger and stronger. This means that the result of this research also supports the results from Aparicio et al. (2019), who have found that informal institutions throughout the country offset the lack of individual factors for those who have no entrepreneurial intentions.

Furthermore, through the results on Diagram 2, both directly and indirectly, the improvement in the performance of sustainable competitiveness progress is specifically determined more through the empirical path of NPD and institutional integration (upper lane) than the traditional lane (bottom lane), through a general path of the theoretical basis of the role of productivity and economic growth as a key to competitiveness success. Thus, critically, the explanation of knowledge integration in the entrepreneurship industry practice can be the main determinant to strengthen the paradigm of the NIE's new theoretical foundation to support healthier and more appropriate decision making, by optimizing the efficient use of resources and maximizing the function of the performance of sustainable competitiveness progress. Thus, the path analysis results in Fig. 2 can serve as a basis for strong arguments as well as novelty of originality to explain more simply about the importance of integration and collaboration in optimizing the use of existing resources on an ongoing basis. The results of this study have 
also been based on the research recommendation from Rosen and Kishawy (2012) who stated that wider collaboration is needed to understand and apply the importance of sustainable integration of manufacture and design, along with other objectives such as function, competitiveness, profitability, and productivity.

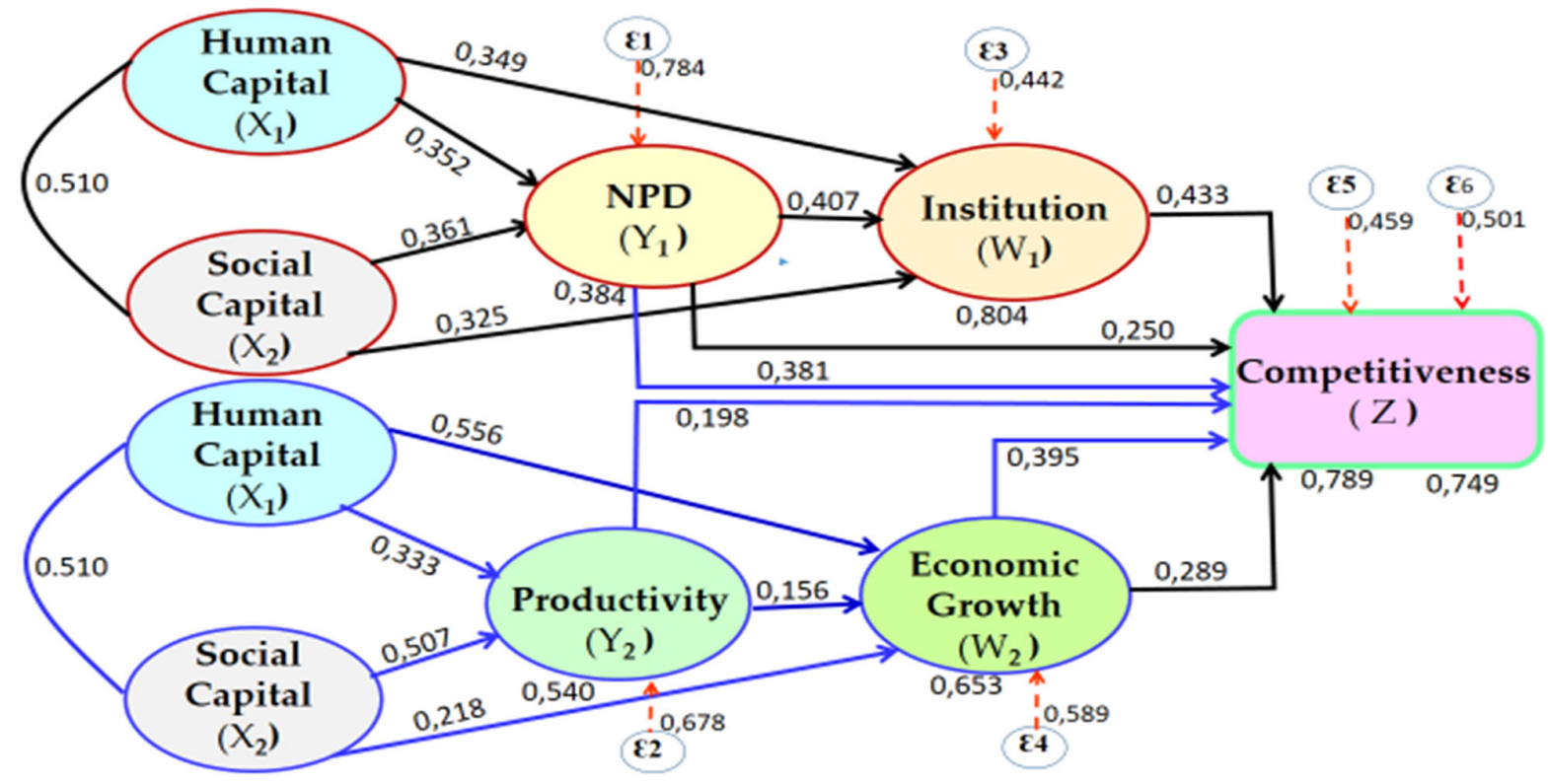

Fig. 2. The research results of path analysis diagram of multiple path correlational recursive form

The critical analysis that the influence of human capital on the entrepreneurial business environment in the research area becomes ambiguous is when the emergence of new products of innovation results that tends to be easily imitated, so that the emergence of 'dirty' new products become ineffective and not productive; thus, the role of human capital on NPD and productivity becomes smaller than the role of social capital. The transition process of the decline of the role of human capital into the increasing role of social capital in this study can also be referred to as 'sharing economy', as the research results from Anatoliy et al. (2019). In other words, institutional theory can be stated similarly as the process of institutional change from the Y matrix to the base of the X matrix (Radiva, 2018; Kirdina-Chandler, 2017, 2019). This study also supports the results from (Savioli, 2016), who stated that an economic process consists of interactions between humans, exploiting social capital of people who are endowed with certain cultures, identities, and education (human capital). Therefore, in this study, it is emphasized that one of the main conditions for the emergence of the development of 'sharing economy' is through the increasing role of social capital, which can occur because of the quality of human capital capacity as its main asset that has a unique social personality that is creative and innovative for mutual diversity to achieve progress in welfare with the family and surrounding community in a sustainable manner. Moreover, the results of this empirical research found a new concept that can strengthen the theory as explained above, that the new economic institutions (NIE) tend to be mainly formed from the institutional environment of native and natural social entities, because they are more driven by togetherness (sharing) factors, so it is not solely because of the encouragement of monopolization economic factors and globalization factors, or the new market economy system as in the basis of the $\mathrm{Y}$ and $\mathrm{X}$ matrix theory explained above.

\section{Conclusion}

The development of innovation technology not only results in the development of new products (NPD), but also produces new ways. A new institution is the best new way because of technological innovation to achieve sustainable competitiveness progress. The role of an institution that is built and formed from the collaboration of human capital and social capital competencies which subsequently produced NPD and productivity, as the main driving force in increasing quality economic growth and sustainable economic and community welfare. At present and in the future, empirically, sustainable competitiveness progress and its contribution to community welfare will be increasingly needed. In the practice of entrepreneurship in the region, the role of productivity theory as the key of competitiveness must be collaborated with the role of NPD and institutional integration so that sustainable competitiveness progress can be realized. The results of the research of integration and collaboration can also become a reinforcement of the basic concepts of the NIE theory which is now increasingly growing. The important role of human capital theoretically and empirically has been recognized to be able to drive increased productivity and encourage economic growth. Meanwhile, the role of social capital tends to be stronger in driving the progress of sustainable competitiveness. Therefore, these various important roles must be integrated and collaborated with the important role of institutions as the best way to optimize the use of resources (human capital and social 
capital), and to maximize economic performance, increasing NPD output, productivity, economic growth, and sustainable development progress.

New product development is the output of technological innovation advancement, while institution is the best way that must be developed as a rule of the game and a strong foundation for decision makers to achieve sustainable development and competitiveness progress. If productivity and economic growth is the main key success to achieve sustainable competitiveness, the NPD and institutional integration is the main determinant of sustainable competitiveness progress. In the development of a new economy (sharing economy), the important role of productivity performance is still able to increase economic growth, but the role as the main key to competitiveness can be weakened. Therefore, as a guideline for policy implications, it is not enough just to increase productivity performance and economic growth as the main key to competitiveness, but it also requires collaboration of various fundamental factors and NPD with institutional integration as a unified whole and the best main determinants in achieving progress in competitiveness for community welfare in a sustainable manner.

\section{References}

Acemoglu, D., Gallego, F., \& Robinson, J. A. (2014). Institutions, human capital and development. The Annual Review of Economics, 6(1), 875-912. https://doi.org/10.1146/annurev-ec-6.

Acemoglu, D., \& Robinson, J. (2010). The Role of Institutions in Growth and Development. Review of Economics and Institutions, 1(2), 1-33. https://doi.org/10.5202/rei.v1i2.1.

Acs, Zoltan, J., Estrin, S., Mickiewicz, T., \& Szerb, L. (2018). Entrepreneurship, institutional economics, and economic growth: an ecosystem perspective. Small Business Economics, 51(2), 501-514. https://doi.org/10.1007/s11187-018-0013-9.

Ali, M., Egbetokun, A. \& Memon, M. (2018). Human capital, social capabilities and economic growth. Economies, 6(2), 1-18.

Anatoliy, T., Maryna, R., \& Viktoriia, K. (2019). Institutional models of the new economy development Modelos institucionales del desarrollo de nueva economía. Revista Espacios, 40(22), 29-41.

Aparicio, S., Urbano, D. \& Stenholm, P. (2019). Institutions in Attracting the Entrepreneurial Potential: A Multilevel Approach. Academy of Management Proceedings, 1, 15408.

Aparicio, S., Urbano, D., \& Gomez, D. (2018). Entrepreneurship and regional economic growth in Antioquia: An empirical analysis, Economics and Business Letters, 7(2), 84-91.

Arzenšek, M., Bider, D., \& Ferjančič, U. (2016). Institutions \& Economic Development: A More Complete View to Understanding Economic Growth. Review of Economics \& Economic Methodology, I(1), 70-87.

Bjørnskov, C., \& Foss, N. J. (2016). Institutions, Entrepreneurship, and Economic Growth: What Do We Know and What Do We Still Need to Know?. The Academy of Management Perspectives, 30(3), 292-315. https://doi.org/10.5465/amp.2015.0135.

Boudreaux, C.J. (2019). Entrepreneurship, Institutions, and Growth: Does the Level of Development Matter? arXiv preprint arXiv:1903.02934, https://arxiv.org/ftp/arxiv/papers/1903.

Bruce, B.M. (2014). Collaboration and Regional Economic Development: A Comparison of North Country, New York and Four Counties, Ontario. A thesis, Master of Arts In Geography: Waterloo, Ontario, Canada, https://uwspace.uwaterloo.ca

Chowdhury, F., Audretsch, D.B., \& Belitski, M. (2019). Institutions and Entrepreneurship Quality. Entrepreneurship Theory and Practice, 43(1), 51-81. https://doi.org/10.1177/1042258718780431

Dhahri, S., \& Omri, A. (2018). Entrepreneurship Contribution to the Three Pillars of Sustainable Development: What Does the Evidence Really Say?. MPRA Paper, No. 84504. https://mpra.ub.uni-muenchen.de/84504

Dias, J., \& Tebaldi, E. (2012). Institutions, human capital, and growth: The institutional mechanism. Structural Change and Economic Dynamics, 23, 300-312.

Januskaite, V., \& Uziene, L. (2018). Intellectual Capital as a Factor of Sustainable Regional Competitiveness. Sustainability, 10,118. https://doi.org/10.3390/su10124848.

Kirdina-Chandler, S. G. (2019). Western and non-Western economic institutional models in time \& geographical space. Terra Economicus, 17(1), 8-23. https://doi.org/10.23683/2073-6606-2019-17-1-8-23.

Kirdina-Chandler, S.G. (2017). Institutional Matrices Theory, or X-and Y-theory: A Response to F. Gregory Hayden. Journal of Economic Issues, 51(2), 476-485.

Pelinescu, E., (2015). The impact of human capital on economic growth. Procedia Economics and Finance, 22, $184-190$.

Popescu, G.H., Sima, V., Nica, E., \& Gheorghe, I.G. (2017). Measuring Sustainable Competitiveness in Contemporary EconomiesInsights from European Economy. Sustainability, 9, 1-26.

Prasetyo, P. E., \& Dzaki, F.Z. (2020). Institutional performance and new product development value chain for entrepreneurial competitive advantage. Uncertain Supply Chain Management, 8(4), 753-760. https://doi.org/10.5267/j.uscm.2020.7.004

Prasetyo, P.E., Setyadharma, A., \& Kistanti, N.R. (2020a). The Role of Social Capital in New Products Development and Business Competitiveness Enhancement, International Journal of Scientific \& Technology Research, 9(3), 1838-1843.

Prasetyo, P.E., Setyadharma, A., \& Kistanti, N.R. (2020b). Social Capital: The Main Determinant of MSME Entrepreneurship Competitiveness. International Journal of Scientific \& Technology Research, 9(3), 6627-6637.

Prasetyo, P.E. (2020a). The Role of Government Expenditure and Investment for MSME Growth: Empirical Study in Indonesia. Journal of Asian Finance, Economics and Business, 7(10), 471-480. https://doi.org/10.13106/jafeb.2020.vol7.no10.471

Prasetyo, P. E. (2020b.) Human Capital as the Main Determinant of Regional Economic Growth, International Journal of Advanced Science and Technology, 29(03), 6261-6267.

Prasetyo, P.E. (2019). The Reliability of Entrepreneurial Productivity as Driver of Economic Growth and Employment. International Journal of Entrepreneurship, 23(4), 1-15.

Rađenović, T., \& Krstić, B. (2017). The impact of human capital development on competitiveness. Entrepreneurship Conference Paper, 104-111. https://doi.org/10.15308/finiz-2017-104-111. 
Radiva, M. (2018). Institutional Modernization of The Global Economy. Baltic Journal of Economic Studies, 4(5), $283-290$.

Rosen, M.A., \& Kishawy, H.A. (2012). Sustainable Manufacturing and Design: Concepts, Practices and Needs. Sustainability, 4, 154-174. https://doi.org/10.3390/su4020154.

Rosen, M.A. (2009). Energy Sustainability: A Pragmatic Approach and Illustrations. Sustainability, 1, 55-80. https://doi.org/10.3390/su1010055.

Savioli, M., \& Patuelli, R. (2016). Social Capital, Institutions and Policymaking. Economics Discussion Papers, No 2016-26, Kiel Institute for the World Economy. http://www.economics-ejournal.org/economics/discussionpapers/2016-26

Šlaus, I., \& Jacobs, G. 2011. Human Capital and Sustainability. Sustainability, 3, 97-154. https://doi.org/10.3390/su3010097.

Urbano, D., Aparicio, S. \& Audretsch, D. (2019). Twenty-ve years of research on institutions, entrepreneurship, \& economic growth: what has been learned?, Small Business Economics, 53(1), 21-49. https://doi.org/10.1007/s11187-018-0038-0

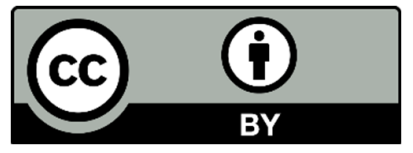

(C) 2021 by the authors; licensee Growing Science, Canada. This is an open access article distributed under the terms and conditions of the Creative Commons Attribution (CCBY) license (http://creativecommons.org/licenses/by/4.0/). 